\title{
Contextual Non-financial Analysis of Annual Reports of Slovak, Turkish and Ukrainian Companies
}

\author{
Zuzana Kubaščíková ${ }^{1, *}$, Miloš Tumpach ${ }^{1}$, Zuzana Juhászová ${ }^{1}$,Emin Zeytinoglu and \\ Lyudmyla Chyzhevska ${ }^{3}$ \\ ${ }^{1}$ University of Economics in Bratislava, Faculty of Business Informatics, Department of Accounting \\ and Auditing, Dolnozemská 1, 85235 Bratislava, Slovakia \\ ${ }^{2}$ Dumlupinar University, Faculty of Accounting, Department of Accounting, Kirazpinar, Kutahya, \\ Turkey \\ ${ }^{3}$ Zhytomyr Polytechnic State University, Faculty of Business and Service sector, Department of \\ Accounting and Auditing, Chudnivska Street b. 103, 10005 Zhytomyr, Ukraine
}

\begin{abstract}
.
Research background: Various sources of information are available to assess possible and future financial results for stakeholders. The annual reports of companies should also include information on the risks of the environment in which the company operates and doing business. Textual analysis of annual reports can assess behavioral aspects of accounting as a source of information for decision-making.

Purpose of the article: With the growing range of annual reports being observed, or the growing interest of investors or analysts in the nonfinancial information from annual reports stakeholders find annual reports in support of their decisions.

Methods: For the purposes of comparison, we selected companies from the growing economy of the Slovak Republic, Turkey and country at war, Ukraine. In our paper we examined whether the tone and structure of language applied in annual reports changed over time alongside the changing economic growth in the country and whether there are any differences in narrative disclosure between Slovak, Turkish and Ukrainian companies. Then we compared the results obtained in order to propose reliable recommendations and tested whether it is possible to detect uncertainty of business environment in annual reports or companies by textual analysis.

Findings \& Value added: Based on our results we conclude that nonfinancial "narrative" data could also correlate with changing GDP growth of the country. The annual reports are to point out the reality without distortion, which was confirmed to us in the analysis.
\end{abstract}

Keywords: annual reports; textual analysis; narrative information

JEL Classification: $M 49 ; D 91 ; G 41$

*Corresponding author: zuzana.kubascikova@euba.sk 


\section{Introduction}

Despite the topic of textual analysis of financial data not being a new topic over the last 4 years it has been plagued by new wave of interest by researchers. [12] Scientists show a wide variety of techniques that can be used for an efficient and quick textual analysis of financial data and explain what managers and accounting professionals are hiding in the texts of annual reports and other corporate documents. [13] Scientists all over the world address the different types of analytic of narrative textual data and it is possible to find their results in various databases of scientific papers.

A couple of conclusions can be drawn from the literature review as follows:

- 416 scientific papers have been published on the topic of textual analysis in business finance (business, management, accounting) in both databases (Scopus and Web of Science) during the period reported,

- a substantial increase in the number of scientific articles has been observed,

- the number of publications on the topic of textual analysis is steadily increasing, which shows a growing interest from the academic community and research on the topic,

- the number of publications from USA published each year has risen sharply in the last years, including both databases,

- the number of citations is exponentially growing, which is associated with the increasing number of publications,

- high-impact factors publications do not have a high impact on citations,

- the most cited (849 times vs. 715 times) in both databases is the paper on When is a Liability Not a Liability? Textual Analysis, Dictionaries, and 10-Ks [9].

Loughran and Mcdonald in his highly cited paper [9] developed and alternative negative word list which better reflects financial text tone and they proved that the word lists used for other disciplines misclassify common words in financial texts. They showed that almost $75 \%$ of negative word counts in $10-\mathrm{K}$ filings based on the Harvard dictionary are in fact not negative for purposes of financial reporting.

There are few papers which examined whether the tone and complexity of annual papers relate to a companies'financial situation. Other papers analyzed whether textual analysis of annual reports vary across phases of the corporate life cycle. Bakarich, Hossain, Weintrop proved that companies provide qualitatively different disclosures and shows that disclosure varies according to cycle stages. [3]

Almost all papers focus on analysis of annual reports or other company financial documents in English because the majority of software tools are set for English. But the first papers that analyze annual reports and other financial documents in other languages are already starting to appear. El-Haj et al. analyzed Portuguese reports and using a random sample of 586 reports their method confirmed an accuracy of $95 \%$. [4]

Loughran and Mcdonald published another paper in 2016 in which they reviewed textual analysis papers from previous years and they concluded that a traditional concept of readability and Fox Index is ineffective because measuring sentence length does not determine comprehension and most long multisyllabic words are easily understood in financial documents [10].

People's judgments based on information in annual reports are considered intuitive if they come to mind as perceptions - quickly and without any effort. Kahneman introduced the theory of the two mental systems when people make judgments and make decisions [5]. According to the theory of the two mental systems, most judgments and preferences are intuitive, but they may be modified or replaced by other judgments and preferences based on the deliberative practices of the mind. The human mind consists of two systems. First system "works automatically and immediately, with little or no effort and no sense of self- 
control" [6]. The first system works fast, is easy, simple and spontaneous, but it is difficult to control. The second system "pays attention to the strenuous mental activity including complex calculations" [6]. The operation of the second system is slower, systematic, difficult, relatively adaptable and intentionally controlled. The first system continuously creates intuitive impressions, intentions and feelings. If everything goes smoothly, the second system will usually acknowledge the suggestions of the first system with no or little adjustments, whereat intuition turns into belief. People usually believe in their impressions and behave in accordance with their desires. People are not used to thinking hard because they often believe in the fast and the random judgment coming to mind. Intuitive judgments are influenced by ideas perceptions and can also be triggered by language.

People assess the possible results of their decisions in that they classify them according to preference, not on the basis of mathematics or logic, but use intuitive and heuristic procedures. People transform possible results on probabilities and assess potential gains or losses to ones subjective reference point. Deviations from rationality in people's behavior most often arise as a coding and analysis of possible gains or losses to certain reference points (for example, current volume of assets or monthly income in employment), combining and estimating the probabilities of potential outcomes, the decisions that people make, separating risky from risk-free options, ignoring some possible consequences of decisions, simplification of complicated and demanding decision results, scanning and eliminating unlikely possibilities. [6].

\section{Methodology and Data}

The annual report is one of the most important means of companies' communication. If a company wants to be successful among competitors, it should see the annual report and its quality as an important aspect of achieving this goal. [11] In this paper, we analyzed non-financial data in the annual report by applying a text analysis tool.

According to the World Bank Ukraine is a developing low income country oriented toward agriculture industry. Their economy was affected by the financial crisis, accession process to EU and Russian intervention in Ukraine which ended up by the annexation of Crimea. The Donbass conflict affected economic situation in Ukraine radically. The crisis and lasting hybrid/civil war conflict increased the level of risk in the business environment and caused economic disbalances. We chose Slovakia for comparison, due to the fact that Slovakia does not pose a risk for investors and businessmen, investors have confidence in the Slovak environment, as it is a growing economy that is part of the European Union and is not part of any conflict that would not cause uncertainty in a business environment. The second country for comparison we choose Turkey, also growing economy but with lower investors confidence due to fact that they are not part of European Union and their territory is politically pretty turbulent.

For the purposes of the analysis, we selected 400 annual reports from Turkey, Slovakia and from Ukraine for the years 2008-2018. We could only choose only annual reports prepared in English so our selection was significantly reduced. When selecting, we tried to choose companies from different sectors, so that we could compare the results of the analysis with each other and then define certain conclusions. We obtained the annual reports of individual companies via the website www.annualreports.com. This site is intended to compile the most complete and up-to-date list of annual reports. Some annual reports were gained directly from web pages of participating companies.

We focused on the evaluation of annual reports through a text analysis tool, which evaluates their focus according to the sentiment of the words used. Using a text analysis tool and various methods, we will try to achieve the main goal - the analysis of nonfinancial data in annual reports. If we want to obtain comparable information from the 
annual reports of different companies, we must make sure that we use annual reports that have approximately the same scope. We tested the hypothesis whether it is possible to detect uncertainty of the business environment in annual reports or companies by textual analysis. As a source of GDP growth data of selected countries the web page https://countryeconomy.com/gdp.

For text analysis we used Linguistic Inquiry and Word Count (LIWC 2015) software. This software analyses the text and calculates the percentage of words that reflect different emotions, thinking styles, social interests and sentence structure. Language categories have been created to capture social and psychological conditions. The software contains built-in dictionaries and the text analysis module compares each word with a defined dictionary. Identifying words that are associated with relevant psychological categories. Following the identification and counting of all words in a given text, it calculates the percentage of total words that match the categories in the dictionary. The text analysis module identifies and categorizes words and the core of the program is a group of dictionaries. For each word in the dictionary, there is a corresponding dictionary entry that defines one or more categories of words. As with every software also LIWC2015 has several blind spots. Care must be taken when short texts are analyzed and when there is sarcasm, irony or metaphors used. However, as we analyze non-financial data in annual reports, we can rule out the possibility of encountering a non-formal writing style and also the length of annual reports is sufficient for this purpose. [1]

\section{Results and Discussion}

Cognitive deviations from rationality are the result of incorrect collection or analysis of information, especially when deciding on potential gains or losses. [8] Most deviations from rationality in decision making are cognitive. We may also apply mental account policies to users of accounting information. The priority decision makers in companies are the owners who assess the financial goals of the company (profitability, solvency, etc.) and classify their investments into mental accounts. The financial goals of the company and the mental accounts of the owners are lined up according to importance. For example, if the owners' goal is to maintain value assets and at the same time, they have an aversion to risk, they assign to the given mental account low-risk investment. Concerning different rules for mental accounts owners find it difficult to assess the investment and financial objectives of the company. Owners' decision making about investing capital in a business should be based on a thorough analysis of accounting information. The rules of mental accounts can create conditions when owners' decisions do not have to be based on financial information from accounting, but may be influenced by non-financial information from annual reports.

For analyzing we have chosen four categories of emotions - risk, reward, positive emotions and negative emotions.

Table 1. Expression of emotions focused on risk in annual reports (in percentage).

\begin{tabular}{|c|c|c|c|}
\hline & Average TR & Average SK & Average UA \\
\hline $\mathbf{2 0 0 8}$ & 0.8394 & 0.9200 & 0.9200 \\
\hline $\mathbf{2 0 0 9}$ & 0.9518 & 0.9768 & 0.9067 \\
\hline $\mathbf{2 0 1 0}$ & 0.9132 & 0.9308 & 1.0533 \\
\hline $\mathbf{2 0 1 1}$ & 0.8889 & 0.9129 & 0.9433 \\
\hline $\mathbf{2 0 1 2}$ & 0.8657 & 0.8904 & 1.0100 \\
\hline $\mathbf{2 0 1 3}$ & 0.9843 & 1.004 & 1.0300 \\
\hline $\mathbf{2 0 1 4}$ & 0.9597 & 0.9709 & 1.0800 \\
\hline $\mathbf{2 0 1 5}$ & 0.9250 & 0.9425 & 1.1133 \\
\hline $\mathbf{2 0 1 6}$ & 1.0088 & 1.0106 & 1.0633 \\
\hline
\end{tabular}




\begin{tabular}{|l|l|l|l|}
\hline $\mathbf{2 0 1 7}$ & 0.9719 & 0.9763 & 0.9700 \\
\hline $\mathbf{2 0 1 8}$ & 1.0347 & 1.0394 & 1.1300 \\
\hline
\end{tabular}

Source: own processing in LIWC2015

Risk is expressed by words problems, protection, prevent, safety, hazard, security etc. Reward is expressed by words get, approach, promote, take etc. [7]

Table 2. Expression of emotions focused on reward in annual reports (in percentage).

\begin{tabular}{|c|c|c|c|}
\hline & Average TR & Average SK & Average UA \\
\hline $\mathbf{2 0 0 8}$ & 0.8706 & 1.0600 & 0.8467 \\
\hline $\mathbf{2 0 0 9}$ & 0.9323 & 0.9423 & 0.8433 \\
\hline $\mathbf{2 0 1 0}$ & 0.9458 & 0.9558 & 0.7767 \\
\hline $\mathbf{2 0 1 1}$ & 0.9011 & 0.9074 & 0.9033 \\
\hline $\mathbf{2 0 1 2}$ & 0.8704 & 0.8800 & 0.8767 \\
\hline $\mathbf{2 0 1 3}$ & 0.9303 & 0.9403 & 1.1033 \\
\hline $\mathbf{2 0 1 4}$ & 0.9675 & 0.9753 & 0.7833 \\
\hline $\mathbf{2 0 1 5}$ & 0.9459 & 0.9584 & 0.7900 \\
\hline $\mathbf{2 0 1 6}$ & 0.9681 & 0.9728 & 0.7700 \\
\hline $\mathbf{2 0 1 7}$ & 0.9878 & 0.9869 & 0.7833 \\
\hline $\mathbf{2 0 1 8}$ & 0.9900 & 0.9903 & 0.8133 \\
\hline
\end{tabular}

Source: own processing in LIWC2015

Positive emotions from analyzed annual reports are according to the software expressed by the following words - forgiving, healthy, support, respect, sure, freedom, challenges, greater, encourage, care, importance, helps, save, agreed, satisfy, improvement, well, safety, security etc.

Table 3. Expression of emotions focused on positive emotions in annual reports (in percentage).

\begin{tabular}{|c|c|c|c|}
\hline & Average TR & Average SK & Average UA \\
\hline $\mathbf{2 0 0 8}$ & 2.3783 & 2.8433 & 2.2067 \\
\hline $\mathbf{2 0 0 9}$ & 2.6332 & 2.6618 & 2.1833 \\
\hline $\mathbf{2 0 1 0}$ & 2.7054 & 2.7329 & 2.4600 \\
\hline $\mathbf{2 0 1 1}$ & 2.4444 & 2.4667 & 2.5000 \\
\hline $\mathbf{2 0 1 2}$ & 2.4378 & 2.4681 & 2.5700 \\
\hline $\mathbf{2 0 1 3}$ & 2.4521 & 2.5189 & 2.9000 \\
\hline $\mathbf{2 0 1 4}$ & 2.5113 & 2.5338 & 2.5600 \\
\hline $\mathbf{2 0 1 5}$ & 2.4763 & 2.5066 & 2.5667 \\
\hline $\mathbf{2 0 1 6}$ & 2.5313 & 2.5388 & 2.4700 \\
\hline $\mathbf{2 0 1 7}$ & 2.4772 & 2.4875 & 2.4433 \\
\hline $\mathbf{2 0 1 8}$ & 2.5234 & 2.5422 & 2.5567 \\
\hline
\end{tabular}

Source: own processing in LIWC2015

Negative emotions are for example: problems, abuses, exhaustible, hazard, critical.

Table 4. Expression of emotions focused on negative emotions in annual reports (in percentage).

\begin{tabular}{|c|c|c|c|}
\hline & Average TR & Average SK & Average UA \\
\hline $\mathbf{2 0 0 8}$ & 0.7022 & 0.7500 & 0.7800 \\
\hline $\mathbf{2 0 0 9}$ & 0.8205 & 0.8414 & 0.7867 \\
\hline $\mathbf{2 0 1 0}$ & 0.7825 & 0.7954 & 0.9333 \\
\hline $\mathbf{2 0 1 1}$ & 0.7659 & 0.7893 & 0.8300 \\
\hline $\mathbf{2 0 1 2}$ & 0.7250 & 0.7468 & 0.8900 \\
\hline $\mathbf{2 0 1 3}$ & 0.8487 & 0.8663 & 0.9500 \\
\hline $\mathbf{2 0 1 4}$ & 0.8244 & 0.8369 & 1.0533 \\
\hline
\end{tabular}




\begin{tabular}{|l|l|l|l|}
\hline $\mathbf{2 0 1 5}$ & 0.8000 & 0.8184 & 1.0700 \\
\hline $\mathbf{2 0 1 6}$ & 0.8491 & 0.8575 & 1.0033 \\
\hline $\mathbf{2 0 1 7}$ & 0.8309 & 0.8419 & 0.9167 \\
\hline $\mathbf{2 0 1 8}$ & 0.8744 & 0.8853 & 1.0467 \\
\hline
\end{tabular}

Source: own processing in LIWC2015

Based on the performed analysis, we can state that in the Ukrainian annual reports negative emotions clearly prevail over positive ones when decreasing GDP is expected in the following period. We assessed that this is due to the composition of stakeholder groups of companies in this environment. Products from analyzed companies are often exported to the Russian Federation and they are sensitive to the Ukrainian-Russian conflict. At the first glance, risks are always associated with negative emotions. However, annual reports compilers focus primarily on positive attitudes, opinions aimed at reward and satisfaction. We can state that the annual reports and their non-financial data from the Ukrainian companies have certainly had a certain degree of informative value for all known stakeholders (customers, employees, regulators, senior management).

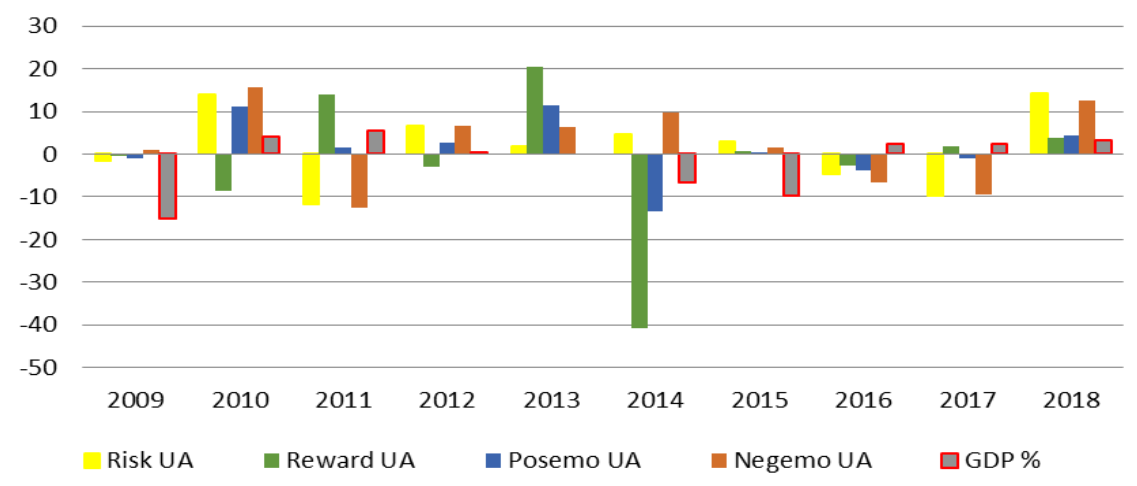

Fig. 1. Expression of emotions focused in Ukrainian annual reports compared with GDP. Source: own processing

In Turkish annual reports there is not such a high and obvious correlation of emotions in annual reports and GDP growth at first sight, but looking into the details we can also confirm it. We can state that trend of prevailing positive emotions over negative ones was repeated in analyzed annual reports but the growth or decrease of these emotions in comparison to the previous year is not always so one-sided. Risk is generally associated with the certainty of higher reward and reward with a positive emotion, but this was not confirmed in annual reports sentiment analysis. Also, the results are influenced by the fact that analyzed Turkish companies are from various industrial sectors (airlines, car production, food industry, telecommunication industry etc. not only in agriculture industry as in the example from Ukraine and therefore the companies face different level of risks that their industry brings. 


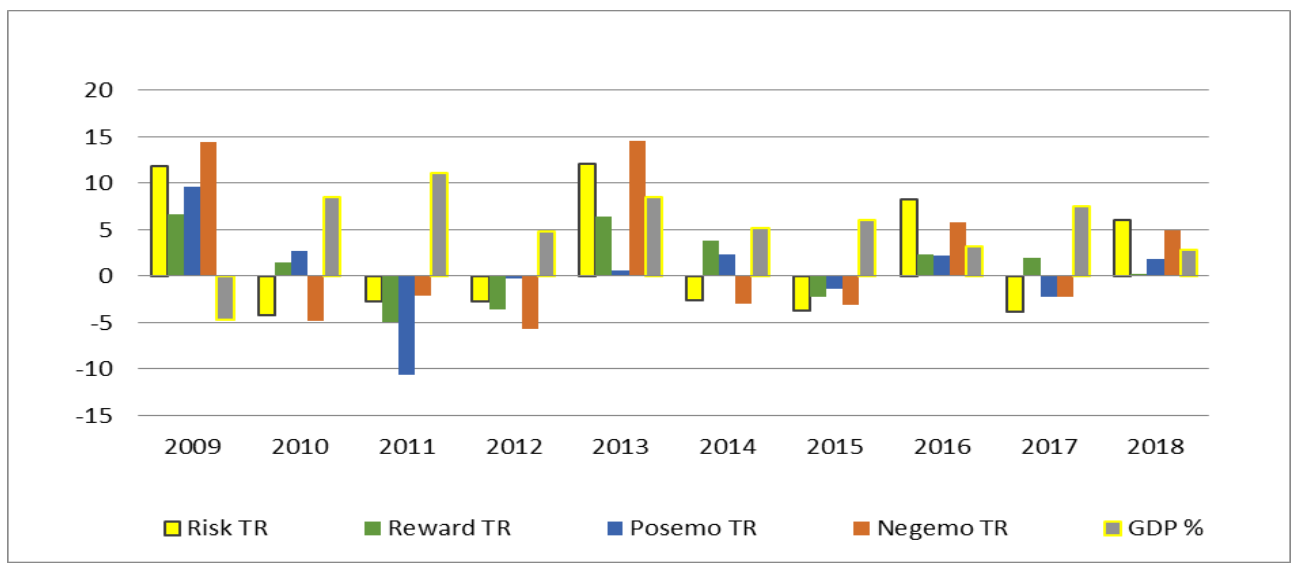

Fig. 2. Expression of emotions focused in Turkish annual reports compared with GDP.

Source: own processing

The annual reports of companies from Slovakia confirmed the opposite trend. In all years the positive emotions growth or decrease between the years corelated with economic growth. This follows from the nature of the companies themselves, mostly companies from the car industry. The car industry clearly has a negative impact on the environment, and the compilers of the annual reports cannot omit these impacts (risk and negative emotions) in the annual reports however there was economic growth.

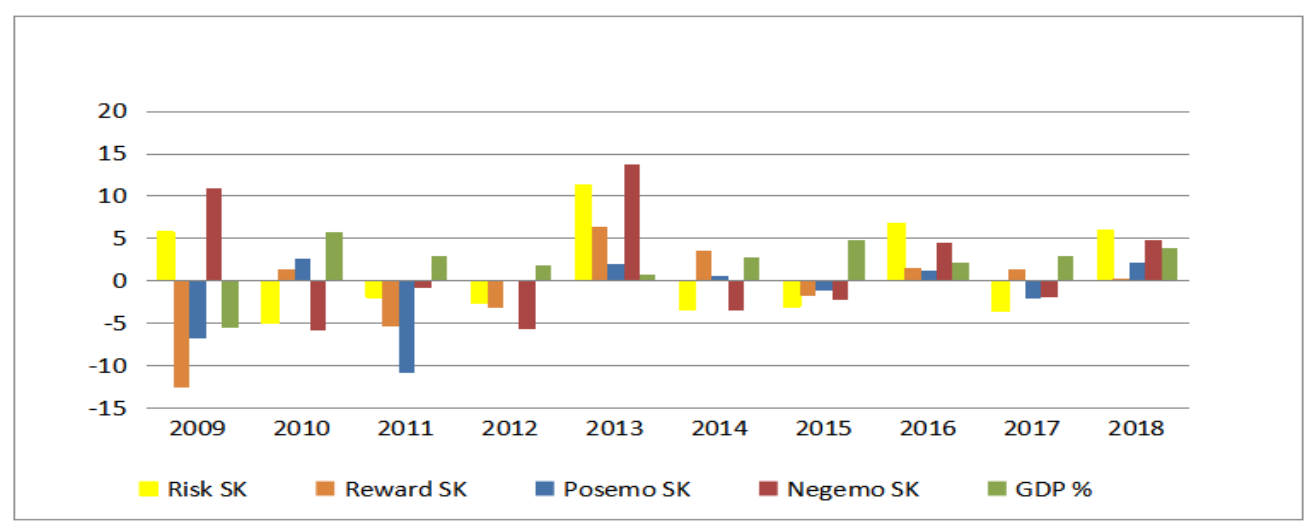

Fig. 3. Expression of emotions focused in Slovak annual reports compared with GDP.

Source: own processing

The analysis of sentiment in annual reports is important because expressed sentiment can influence the decision-making process of stakeholders. Theory of limited rationality describes [14] that people do not always try to maximize their own benefits based on a specific decision-making process, as they cannot obtain and evaluate all necessary information. Even if people had access to all necessary information to make absolute rational decisions, their minds would not be able to evaluate this information correctly. The human mind has limited performance and cognitive capacity. People face constraints on the relationship as well and how much information they can evaluate at the specific time interval. Some people are more effective at evaluating information than others, but ultimately no one has unlimited possibilities to evaluate all available information. People's decision-making abilities are therefore limited by the computational capacity of the mind (a certain limit of the human brain to process and understand information). People need to 
choose what information to evaluate, resulting in their limited rationality. The theory of limited rationality describes people who "can only understand a limited amount of information in a limited time, and for this reason, they do not always make the best decisions, especially in complicated situations. [14] The extent of limited rationality can be influenced by the way the information is provided to users in annual reports.

Annual reports are to point out the reality without distortion, which was confirmed to us in the analysis. The compilers of the annual reports hereby ensure that the annual reports are a true means of communication between the company and all stakeholders.

\section{Conclusions}

Accounting is a source of information about the company for users. The primary users of accounting information are owners, financial and other creditors. Behavioral finance is a part of behavioral economics "which applies the knowledge of cognitive and emotional deviations from rationality in economic decisions in financial markets" [2]. Behavioral accounting, like behavioral economics, focuses on deviations from rationality in human behavior. The interconnection of accounting and behavioral economics is based on the position of owners, financial and other creditors, who may deviate from rationality in judgment or decision-making. Behavioral aspects of accounting as a source of information for decision-making result from the relationship between accounting and behavioral economics.

Non-financial data as well as financial data are intended for various stakeholders. Information in companies' annual reports should be legible for potential investors, employees, clients, regulators. Annual reports within their company revealing their activities, results, developments and future trends are available from available sources of information. The annual reports also include non-financial information, which gives broader insights into the business and performance of the company. With the growing range of interest rate reports being observed, or the growing interest of investors or analysts in the non-financial information from past reports they find in support of their decisions. In this paper we tested the hypothesis whether it is possible to detect uncertainty of the business environment in annual reports or companies by textual analysis and we found out that correlates with the changing GDP growth of the country.

This article is an output of the project APVV no. APVV-16-0602 "Enhancement of the relevance of the accounting data in the SR - from expenses to value".

\section{References}

1. Andrejovska, A., Banociova, A. (2013). Payment discipline in business environment. In. International Conference on Emerging Markets Queries in Finance and Business. Procedia Economics and Finance, 15, 1217-1224.

2. Balaz, V. (2009) Riziko a neistota. Bratislava: Veda.

3. Bakarich, K. M., Hossain, M., Weintrop, J. (2019). Different time, different tone: Company life cycle. Journal of Contemporary Accounting and Economics, 15(1), 6986.

4. El-Haj, M., Alves, P., Rayson, P., Walker, M., Young, S. (2019). Retrieving, classifying and analysing narrative commentary in unstructured (glossy) annual reports published as PDF files, Accounting and Business Research, 50(1), 6-34. 
5. Kahneman, D. (2002). Maps of bounded rationality: A perspective on intuitive judgment and choice. [online]. Princeton: 2002. [24. 5. 2020]. Available at: http://www.nobelprize.org/nobel_prizes/economicsciences/laureates/2002/kahnemann-lecture.pdf.

6. Kahneman, D. (2011). Thinking, fast and slow. USA: Farrar, Straus and Giroux, 2011.

7. Kriskova, P., Uzik, J. (2016). Management of audit risk and its impact on the audit of financial statements. Managing and Modelling of Financial Risks, Proceedings of the 8th International Scientific Conference (pp. 460-466). Ostrava, Czech Republic.

8. Kontsyvaya, S., Alborov, R. Kontsevaya, S., Smutka, L., Makunina, I., Turebekova, B. (2019). Accounting and analysis of biological asset transformation results in agricultural companies of the Russian federation. Conference Hradec Economic Days, 10(1), 336-343.

9. Loughran, T., Mcdonald, B. (2011). When is a liability not a liability? Textual analysis, dictionaries, and 10-Ks. Journal of Finance, 66(1), 35-65.

10. Loughran, T., Mcdonald, B. (2016). Textual analysis in accounting and finance: A survey. Journal Accounting Research, 54(4), 1187-1230.

11. Ondrusova, L. (2011). Management decisions leading to ownership transactions. Strategic Management: International Journal of Strategic Management and Decision Support Systems in Strategic Management, 16(3), 18-22.

12. Paksiova, R., Janhuba, M. (2012). Teória účtovníctva v kontexte svetového vývoja. Bratislava: Iura Edition.

13. Parajka, B. (2015). Are information needs of financial entities served by financial statements in the Slovak Republic. Financial Management of Firms and Financial Institutions (pp. 950-957). Ostrava: Czech Republic.

14. Simon, H. (1978). Rational decision-making in business organizations. [online]. Pittsburgh: $1978 . \quad[6 . \quad 5 . \quad 2020]$. Available at: http://www.nobelprize.org/nobel_prizes/economic-sciences/laureates/1978/simonlecture.pdf. 